\title{
PREGNANCY WITH SEVERE MITRAL STENOSIS WITH POST CESAREAN PPH- A CHALLENGE
}

Madhavi U. Santpur' ${ }^{1}$ Unmesh S. Santpur², Manohar ${ }^{3}$, Rajesh Kaul ${ }^{4}$

\section{HOW TO CITE THIS ARTICLE:}

Madhavi U Santpur, Unmesh S Santpur, Manohar, Rajesh Kaul "Pregnancy with severe mitral stenosis with post cesarean PPH- a challenge". Jo urnal of Evolution of Medical and Dental Sciences 2013; Vol. 2, Issue 43, October 28; Page: 8379-8382.

ABSTRACT: Pregnancy with heart disease still continues to be one of the leading causes of maternal mortality. The presence of heart disease amounts to additional burden on the cardio respiratory system of the mother. The critical period extends from the third trimester to the postpartum period. We herewith report a case of pregnancy with severe mitral stenosis (MS) and pregnancy induced hypertension (PIH) for cesarean section which was further complicated by postpartum hemorrhage (PPH). This case was managed by a combination of epidural and general anesthesia for cesarean section with a successful outcome.

INTRODUCTION: Rheumatic heart disease is a major co-morbidity associated with pregnancy. It contributes to $88 \%$ of the heart diseases complicating pregnancy in the tertiary referral centre in India. ${ }^{1,2}$. The common complications of mitral stenosis are pulmonary edema, atrial fibrillation, congestive cardiac failure (CCF), thromboembolism and cardiac arrest. Anesthesia care includes preoperative optimization, intraoperative hemodynamic stabilization, and postoperative pain relief for better maternal and fetal outcomes.

CASE REPORT: A 25 years female, Gravida: 2, Abortion: 1 with 32weeks of amenorrhea had come for safe confinement. The patient was apparently asymptomatic 1week back when she developed breathlessness which was insidious in onset of Grade-3 and progressed to Grade-4 on the 3rd day of admission. There was orthopnea with features suggestive of CCF. Patient was put on iv Furosemide and Digoxin .She had similar complaints 20 days back, which subsided on taking rest. There was no h/o palpitations or recurrent respiratory tract infection, fever, chest pain, hemoptysis, syncopal attacks. On general examination, Patient was pale and had pedal edema. Pulse rate (PR) was 125/min, regular, blood pressure (BP): 160/100 mm Hg. Respiratory rate (RR): 38 breaths/min. Jugular venous pressures were raised. Patient had a loud S1, normal S2, mid-diastolic murmur in mitral area without any radiation and bilateral crepitations. Investigations revealed $\mathrm{Hb}: 10.2 \mathrm{gm} \%$, coagulation profile and LFT were normal, blood Urea: $46 \mathrm{mg} \%$ Serum Creatinine: $1.1 \mathrm{mg} \%$. Electrocardiogram (ECG) showed Bifid P-wave suggestive of P-mitral, with prominent R wave in V1 and V2. 2D ECHO revealed mitral valve AML doming, PML fixed, restricted mobility, mitral valve area : $1 \mathrm{~cm} 2$ left atrium size: $3.8 \mathrm{cms}$, left ventricle was normal in size with no regional wall motion abnormalities, no thrombus ,ejection fraction of $45 \%$ and pulmonary arterial pressure $25 \mathrm{~mm} \mathrm{Hg}$ .Patient was posted for elective caesarean section under ASA grade III .

Peripheral iv access with $18 \mathrm{G}$ secured .Right subclavian vein cannulation done and CVP was monitored. Antibiotic prophylaxis was administered one hour prior to surgery. Under all aseptic precaution's epidural catheter inserted at L3-L4 space .Patient was premedicated with iv Glycopyrrolate $0.2 \mathrm{mg}$ and iv Ondansetron $4 \mathrm{mg}$. IV Thiopentone $200 \mathrm{mg}$ and iv Succinylcholine 75 


\section{CASE REPORT}

mg was administered. Iv Xylocard $1.5 \mathrm{mg} / \mathrm{kg}$ body wt, was given $90 \mathrm{sec}$ before intubation. $7.5 \mathrm{~mm}$ portex, cuffed endotracheal tube was inserted and connected to EtCO2 monitor and anaesthesia work station .Epidural analgesia was provided by $0.25 \%$ Bupivacaine and 25 micrograms of Fentanyl . $02+\mathrm{N} 20+\mathrm{Iv}$ Vecuronium $4 \mathrm{mg}$ was given for maintenance .CVP maintained around $10 \mathrm{cms}$ of water. A live male baby was delivered. In view of inadequate breathing after reversal, patient was shifted on to elective mechanical ventilation in the post-operative ward with the following ventilator setting MODE- SIMV with Fio2 100\%,tidal volume- 350 ml,RR- 12 breaths/min PEEP$5 \mathrm{~cm}$ of $\mathrm{H} 20$

In the post operative period, $1 \mathrm{hr}$ later she developed $\mathrm{PPH}$ and hypotension $(\mathrm{BP}=70 / 50$, a feeble pulse with PR of 140/min). IM Prostodin, 10 units of oxytocin were added, IV Methargin, per rectum Misoprostol was given and uterine massage was done. Packed cell volume were transfused. IM Prostodin was given thrice at a interval of 15 mins and Misoprostol $800 \mathrm{mg}$ was inserted per rectum. In a period of $3 \mathrm{hrs}$, she had a blood loss of 2.0 liters and was transfused a total of 4 units of PCV, 1 whole blood, 4 units of FFP. With this her uterus retracted well, her vital parameters were stabilized and the next day patient was extubated .Postoperative recovery was uneventful.

DISCUSSION: Anaesthesia management in a pregnant patient with heart disease poses a unique challenge .The understanding of hemodynamic response of the patient and the impact of pregnancy on the cardiac lesion is vital for both, the obstetrician and the anesthesiologist. This increases the risk of adverse maternal and fetal outcome ${ }^{3}$. Mitral stenosis is the most common valvular defect associated with maternal death in pregnancy ${ }^{4}$ Labour, delivery and the immediate puerperium appear to be the times of the maximal risk 5 . Fundamental derangements produced by lesion of mitral stenosis are, obstruction to blood flow from left atrium to left ventricle, increased left atrial pressure and pulmonary capillary venous pressure . ${ }^{6}$ Pulmonary arterial hypertension carries a very high risk during pregnancy (30-50\% mortality). ${ }^{7}$ The predictable changes of pregnancy with both increased volume and heart rate adversely affect cardiovascular haemodynamics in mitral stenosis and clinical deterioration in pregnancy should be expected.8Increase pulmonary blood volume causes pulmonary capillary pressure to exceed colloid osmotic pressure thereby increasing the chances of pulmonary edema. 9,10,11 Wedge pressures increase even more in postpartum period .

Clark and colleagues (1985) hypothesize that this is likely due to loss of the low-resistance placental circulation along with the venous "autotransfusion" from the lower extremities, pelvis, and the now-empty uterus Autotransfusion occurring with labour pains and delivery of the baby can aggravate the conditions and can convert the compensatory stage into a decompensatory stage. ${ }^{12}$ Risk of pulmonary edema is increased if the patient also has pre-eclampsia (resulting in an increase in pulmonary capillary permeability).

The anaesthetic goals are to prevent tachycardia and to preserve sinus rhythm. In addition, it is important to maintain cardiac output and avoid hypovolaemia, vasodilation, hypercarbia and hypothermia .

Either of the two techniques (GA) or regional can be employed. Often concern of profound hypotension after subarachnoid block deters the anaesthetist from choosing spinal anaesthesia .13 Epidural anaesthesia is safer option .General anaesthesia has the disadvantage of increased pulmonary arterial pressure and tachycardia during laryngoscopy and tracheal intubation. Moreover, the adverse effects of positive-pressure ventilation on the venous return may ultimately lead to cardiac failure. ${ }^{14,15,16)}$ Despite these disadvantages, if general anaesthesia is contemplated, 


\section{CASE REPORT}

tachycardia, inducing drugs should be avoided. A beta-adrenergic receptor antagonist and an adequate dose of opioid like fentanyl should be administered before or during the induction of general anaesthesia. Modified rapid sequence induction using etomidate, remifentanyl and succinylcholine is an ideal choice in tight stenosis with pulmonary hypertension .Maintenance of anaesthesia can be carried out with oxygen and nitrous oxide 50:50, Isoflurane, opioids and vecuronium. In general after delivery of the foetus, oxytocin is recommended. An infusion of oxytocin can lower the SVR as well as elevate the pulmonary vascular resistance, resulting in a drop in cardiac output. Care must be taken during its administration. Methylergonovine, or 15methylprostaglandin $F_{2 \alpha}$, produces severe hypertension, tachycardia and increased pulmonary vascular resistance. ${ }^{17,18, \text {, }}$

As in our case there was an exceptional situation, patient had atonic PPH which was not controlled with Oxytocin. The blood loss was more than two liters and so despite of relative contraindication to injection Ergometrine and Carboprost, it had to be given to salvage the life.

CONCLUSION : Management of Heart disease in pregnancy requires a multidisciplinary approach. The choice of anaesthesia technique is not important but stable cardio respiratory status should be the goal .This was achieved by combination of general and epidural anaesthesia .Though Ergometrine and Carboprost are relatively contraindicated in cases of heart disease it may be necessary to administer these drugs. Thus management should be tailored.

\section{REFERENCES:}

1. Bhatla N, Lal S, Behera G, Kriplani A, Mittal S, Agarwal N, et al. Cardiac disease in pregnancy. Int J Gynaecol Obstet 2003;82:153-9.

2. Kannan M, Vijayanand G. Mitral stenosis and pregnancy: current concepts in anaesthetic practice. Indian J Anaesth 2010; 54: 439-44.

3. Siu SC, Colman JM, Sorensen S, et al. Adverse neonatal and cardiac outcomes are more common in pregnant women with cardiac disease. Circulation .2002 May;105(18):2179-84)

4. Hibbard LT. Maternal mortality due to cardiac disease. Clin Obstet Gynecol 1975 Sep;18(3):27.

5. Ueland K. Intrapartum management of the cardiac patient. Clin Perinatol1981Feb; 8(1);155.

6. John M Jackson and Stephen J Thomas. Valvular Heart Disease. In: Joel A Kaplan. Cardiac Anaesthesia, third edition, 1993, chapter 20, 629-680.

7. Burt CC, Durbridge J. Management of cardiac disease in pregnancy. Continuing Education in Anaesthesia, Critical Care \& Pain.2009 Mar;9(2):44-7

8. deSweits Medical Disorders In Obstetric Practice 5th edition,Wiley Blackwell, 2010,chapter 5 Pg 133

9. Philip J Balestrieri. The pregnant patient with heart disease. In: Chestnut D H. Obstetric Anaesthesia: Principles and practice; Chapter 40; Mosby Inc 1999.

10. Mcfaul PB, Dorman JC, Lamki H et al: Pregnancy complicated by maternal heart disease; A review of 519 cases. Br J. of Obst and Gynaec 1988; 95: 861.

11. Warnes CA. Pregnancy and heart disease. In: Libby P, Bonow RO, Mann DL, Zipes DP, editors. Braunwald's Heart Disease: A Textbook of Cardiovascular Medicine. 8th ed. Philadelphia, PA: WB Saunders; 2007.p. 1967-82. ) 
12. Clark SL, Phelan JP, Greenspoon J, et al: Labor and delivery in the presence of mitral stenosis: Central hemodynamic observations. Am J Obstet Gynecol 152:984, 1985

13. Chaudhary S, Salhotra R. Subarachnoid block for caesarean section in severe preeclampsia. J Anaesth Clin Pharmacol 2011;27:169-73.

14. Blaise G, Langleben D, Hubert B. Pulmonary arterial hypertension: Pathophysiology and anesthetic approach. Anesthesiology 2003;99:1415-32.

15. Orme RM, Grange CS, Ainsworth QP, Grebenik CR. General anaesthesia using remifentanil for caesarean section in parturients with critical aortic stenosis: A series of four cases. Int J Obstet Anesth 2004;13:183-7.

16. Chestnut DH. Obstetric anesthesia: Principles and practice. 4th ed. Philadelphia: Mosby Elsevier; 2009. p. 892-5.

17. Secher NJ, Arnsbo P, Wallin L. Haemodynamic effects of oxytocin (syntocinon) and methyl ergometrine (methergin) on the systemic and pulmonary circulations of pregnant anaesthetized women. Acta Obstet Gynecol Scand 1978;57:97-103.

18. Secher NJ, Thayssen P, Arnsbo P, Olsen J. Effect of prostaglandin E2 and F2alpha on the systemic and pulmonary circulation in pregnant anesthetized women. Acta Obstet Gynecol Scand 1982;61:213-8.

\section{AUTHORS:}

1. Madhavi U. Santpur

2. Unmesh S. Santpur

3. Manohar

4. Rajesh Kaul

\section{PARTICULARS OF CONTRIBUTORS:}

1. Assistant Professor, Department of Anaesthesiology, Kamineni Institute of Medical Sciences, Narketpally, Andhra Pradesh.

2. Associate Professor, Departm ent of Obstetrics \& Gynaecology, Kamineni Institute of Medical Sciences, Narketpally, Andhra Pradesh.

3. Professor \& HOD, Department of Anaesthesiology, Kamineni Institute of Medical Sciences, Narketpally, Andhra Pradesh.
4. Professor \& HOD, Department of Obstetrics \& Gynaecology, Kamineni Institute of Medical Sciences, Narketpally, Andhra Pradesh.

\section{NAME ADDRESS EMAIL ID OF THE CORRESPONDING AUTHOR:}

Dr. Madhavi U Santpur

Asst.Prof .in Anaesthesiology

Kamineni Institute Of Medical Sciences .

Nark etpally, Andhra Pradesh.508254

Email - madhavisantpur90@gmail.com

Date of Submission: 18/10/2013.

Date of Peer Review: 19/10/2013.

Date of Acceptance: 22/10/2013.

Date of Publishing: 26/10/2013 